\section{BMJ Open Respiratory Research}

\title{
Acute hypoxaemic respiratory failure in a low-income country: a prospective observational study of hospital prevalence and mortality
}

Arthur Kwizera (D) , ${ }^{1}$ Jane Nakibuuka, ${ }^{2}$ Lydia Nakiyingi, ${ }^{3}$ Cornelius Sendagire, ${ }^{1}$ Janat Tumukunde, ${ }^{1}$ Catherine Katabira, ${ }^{4}$ Ronald Ssenyonga, ${ }^{5}$ Noah Kiwanuka, ${ }^{5}$ David Patrick Kateete, ${ }^{6}$ Moses Joloba, ${ }^{6}$ Daphne Kabatoro, ${ }^{1}$ Diana Atwine, ${ }^{7}$ Charlotte Summers ${ }^{8}$

\section{ABSTRACT}

Introduction Limited data exist on the epidemiology of acute hypoxaemic respiratory failure (AHRF) in low-income countries (LICS). We sought to determine the prevalence of AHRF in critically ill adult patients admitted to a Ugandan tertiary referral hospital; determine clinical and treatment characteristics as well as assess factors associated with mortality.

Materials and methods We conducted a prospective observational study at the Mulago National Referral and Teaching Hospital in Uganda. Critically ill adults who were hospitalised at the emergency department and met the criteria for AHRF (acute shortness of breath for less than a week) were enrolled and followed up for 90 days. Multivariable analyses were conducted to determine the risk factors for death. Results A total of 7300 patients was screened. Of these, 327 (4.5\%) presented with AHRF. The majority (60\%) was male and the median age was 38 years (IQR 27-52). The mean plethysmographic oxygen saturation $\left(\mathrm{SpO}_{2}\right)$ was $77.6 \%$ (SD 12.7); mean $\mathrm{SpO}_{2} / \mathrm{FiO}_{2}$ ratio 194 (SD 32) and the mean Lung Injury Prediction Score (LIPS) 6.7 (SD $0.8)$. Pneumonia (80\%) was the most common diagnosis. Only $6 \%$ of the patients received mechanical ventilatory support. In-hospital mortality was $77 \%$ with an average length of hospital stay of 9.2 days (SD 7). At 90 days after enrolment, the mortality increased to $85 \%$. Factors associated with mortality were severity of hypoxaemia (risk ratio (RR) 1.29 (95\% Cl 1.15 to 1.54), $p=0.01$ ); a high LIPS (RR 1.79 (95\% Cl 1.791 .14 to 2.83$), p=0.01$ ); thrombocytopenia (RR 1.23 (95\% Cl 1.11 to 1.38), $\mathrm{p}=0.01$ ); anaemia (RR 1.15 (95\% Cl 1.01 to 1.31$), p=0.03)$; HIV co-infection (RR 0.84 (95\% Cl 0.72 to 0.97$), p=0.019)$ and male gender (RR $1.15(95 \% \mathrm{Cl} 1.01$ to 1.31$) \mathrm{p}=0.04)$. Conclusions The prevalence of AHRF among emergency department patients in a tertiary hospital in an LIC was low but was associated with very high mortality. Pneumonia was the most common cause of AHRF. Mortality was associated with higher severity of hypoxaemia, high LIPS, anaemia, HIV co-infection, thrombocytopenia and being male.

\section{INTRODUCTION}

Acute hypoxaemic respiratory failure (AHRF) is a common cause of hospital admission

\section{Key messages}

What is the prevalence of adult acute hypoxaemic respiratory failure in an acute care clinical setting in an African country and what are the survival outcomes of these patients?

- The mortality among adult patients presenting with AHRF in our study population was very high.

- This study provides the first direct evidence of the burden of AHRF in an African adult population presenting to a hospital emergency department and suggests that the high mortality may be associated with lack of access to advanced oxygen therapy as well as lack of access to ICU admission.

and organ failure around the world. ${ }^{12}$ The severest form of AHRF is referred to as the acute respiratory distress syndrome (ARDS) and defined by the Berlin consensus (acute onset of hypoxaemia with $\mathrm{PaO}_{2} / \mathrm{FiO}_{2}$ ratio $\leq 300 \mathrm{~mm} \mathrm{Hg}$ at a PEEP of $5 \mathrm{~cm} \mathrm{H}_{2} \mathrm{O}$, bilateral infiltrates on chest X-ray, with no need to exclude cardiac disease). Despite technological advances in mechanical respiratory support, the mortality of AHRF and ARDS remain high. ${ }^{23}$ Most of the published literature has focused on ARDS in the developed world. ${ }^{4}$ In a large Scandinavian study, the 90-day mortality rate in patients with AHRF was similar to that in ALI/ARDS, namely, $41 \%$ and $42 \%$, respectively. ${ }^{4}$ In low-income countries (LICs) and especially Africa, where ICU capacities and resources are highly limited, ${ }^{5}$ there is paucity of data to describe the burden and epidemiology of AHRF or ARDS. Furthermore, the epidemiology of ARHF in LICs is poorly understood. One study conducted in Rwanda used a modification of the Berlin definition to determine the incidence of ARDS. $^{6}$ 
We undertook this prospective study among medically ill adult patients presenting to the emergency department in a tertiary hospital in Kampala, Uganda, to determine the prevalence of and 90-day mortality from AHRF. Furthermore, we sought to determine risk factors associated with death in these patients.

\section{METHODS}

\section{Study design}

This study was designed as a prospective, observational, period prevalence study and was conducted in the emergency department of the Mulago National Referral and Teaching Hospital in Kampala, Uganda, between 1 November 2015 and 31 July 2017. Written informed consent was obtained from all study patients or their next of kin.

\section{Patient and public involvement in the study}

Patients and the public were not involved in the design, conduct, reporting or dissemination plans for this study.

\section{Study setting}

Mulago National Referral and Teaching Hospital is a 1500-bed hospital located in Kampala, the capital city of Uganda. This hospital serves the population of Kampala, the capital city of Uganda, with 1.5 million inhabitants as well as the surrounding districts of Mukono and Wakiso with a total catchment population of 4 million people. The emergency department receives between 60000 to 72000 patients per year and is divided into three major areas namely a surgical side handling surgical emergency, a trauma resuscitation area and a medical side for medical emergencies. For purposes of our study we restricted ourselves to the medical side of the emergency department and focused on more severely ill patients with a Modified Early Warning Score $>4$.

A total of 13 nurses, 6 medical officers, 4 intern doctors and 1 full-time attending physician staffed the medical side of the emergency department. In addition, two senior house officers (internal medicine specialty trainees) and an on-call physician provide coverage on a rotational basis. The medical emergency ward was able to provide intermittent vitals monitoring as well as oxygen therapy. The emergency department did not provide non-invasive ventilation. In the emergency ward, patients spend 24 hours, during which a provisional/working diagnosis is initially made, and then after a diagnostic workup and emergency management, it may be amended at 24-hour review when a disposition plan is being made. Patients are then transferred to specialist units to receive further in-hospital care.

The hospital runs one of the two public ICUs in the country. During the study period, the ICU had 12 beds with the ability to ventilate six patients at any one time. It provides ICU services to all kinds of critically ill patients. The ICU can provide mechanical ventilation, postoperative care, intermittent haemodialysis, peritoneal dialysis and basic neurocritical care. Patients in the emergency and intensive care units can get full blood count and blood group tests done free of charge and chemistry panels at a cost.

\section{Study patients}

All patients admitted to the ED with AHRF. AHRF was defined as acute shortness of breath of less than a week, with or without a history of cough, and a pulse oximetry reading of $<91 \%$ on room air. We excluded patients who were younger than 18 years, patients with a poor prognosis, or patients who were unconscious and without a proxy to provide written informed or deferred consent.

\section{Informed consent}

As far as possible, consent was obtained from patients. We obtained consent from the patients' next of kin where the patient was too ill to give consent. In other cases, we obtained deferred consent, for patients who recovered within the study period. Additionally, due to the limited human resource in our setting, family members are often involved in in-hospital patient care and are therefore frequently available within hospital premises and are able to consent. Consent forms were translated into the local vernacular to aid communication.

\section{Medical management of study patients}

On recruitment, all patients received continuous oxygen therapy by nasal prongs $(6 \mathrm{~L} / \mathrm{min})$ or venturi masks $(10 \mathrm{~L} / \mathrm{min})$ to provide at least $\mathrm{FiO}_{2}$ of 0.4 to maintain $\mathrm{SpO}_{2}$ levels above $91 \%$ or as best as possible. This population received treatment with conventional oxygen therapy (patients got oxygen therapy by face mask or nasal prongs with flow rates titrated against $\mathrm{SPO}_{2}>91 \%$ or as best as possible) and pneumonia management was in accordance with Ugandan national treatment guidelines (https://www.health.go.ug/sites/default/files/Uganda_ Clinical_Guidelines_2016_FINAL.pdf). We referred patients who deteriorated further to the ICU as and when resources and bed capacity permitted.

Our study defined anaemia as haemoglobin $<8 \mathrm{~g} / \mathrm{dL}$, thrombocytopenia as platelets $<100 \times 10^{9} / \mathrm{L}$, leucocytosis as white cell count $>12 \times 10^{9} / \mathrm{L}$ and leucopenia as white cell count $<4 \times 10^{9} / \mathrm{L}$. $\mathrm{SPO}_{2}<85 \%$ and mean arterial pressure $<65 \mathrm{~mm} \mathrm{Hg}$ were considered low.

\section{Data collection and processing}

Using a standardised questionnaire, the study team obtained information on selected sociodemographic characteristics including age, gender, smoking status and firewood exposure. Additionally, clinical information such as previous health status and admission diagnosis as well as clinical and laboratory parameters (including predisposing conditions such as shock, sepsis, HIV status, pneumonia and risk modifiers such as need for higher 
$\mathrm{FiO}_{2}$, hypoxaemia) were obtained to compute the Lung Injury Prediction Score (LIPS). LIPS is a validated score in which one can incorporate a series of routinely available risk factors and modifiers to predict which patients will develop ARDS. ${ }^{7}$ In this model a LIPS of 4 predicts development of ARDS. Clinical notes were reviewed 24 hours after admission for change of or additional diagnoses.

In the absence of arterial blood gas results, we used the widely accepted and validated $\mathrm{SpO}_{2} / \mathrm{FiO}_{2}$ ratio to represent severity of hypoxaemia at admission. We used the $\mathrm{SpO}_{2} / \mathrm{FiO}_{2}$ ratio $<315$ as our threshold ratio for ARDS. ${ }^{8}$ In all patients, pulse oximetry was measured by conventional two-wavelength finger pulse oximeters. We considered the worst readable value of $\mathrm{SpO}_{2}$ at admission for our data.

At the end of each participant-researcher contact, case report forms were checked for completeness. We double entered the data into a computerised database (EpiData V.3.1)

\section{Study end points}

The primary outcome was the prevalence of AHRF among study patients. The secondary outcome was 90-day mortality and factors associated with mortality.

\section{Statistical analysis}

We conducted an 18-month period prevalence study. Prevalence of AHRF was computed using the total number of patients included as the denominator, and patients with AHRF as the numerator. Quantitative variables were described as mean (SD) or median (25th-75th centiles), as appropriate, and compared using Student's t test or the Wilcoxon-Mann-Whitney test. Qualitative variables were described as counts $(\%)$ and compared using the $\chi^{2}$ or the Fisher's exact test, as appropriate. The modified Poisson regression was used to determine the factors associated with mortality and this is expressed as risk ratios (RRs) with a two-sided $p$ value level of significance set at 0.05 . We included variables found to be associated with mortality in other acute care AHRF-related studies in our multivariate model, although they may not have been statistically significant at bivariate analysis.

\section{RESULTS}

We screened a total of 7300 acutely ill patients during the 18-month study period from 1 November 2015 to 31 July 2017. Of these, 327 patients met the eligibility criteria for AHRF. We excluded 6972 patients (figure 1). This represented a prevalence of acute respiratory failure of $4.5 \%$. There was no difference between age and sex distribution at the screening and enrolment stages. The median age was 38 years (IQR 27-52) and the majority of the study patients $(60 \%)$ was male (table 1$)$. Of the 327 who presented with acute respiratory failure, 310 (94.5\%) reported no previous history of acute respiratory failure.

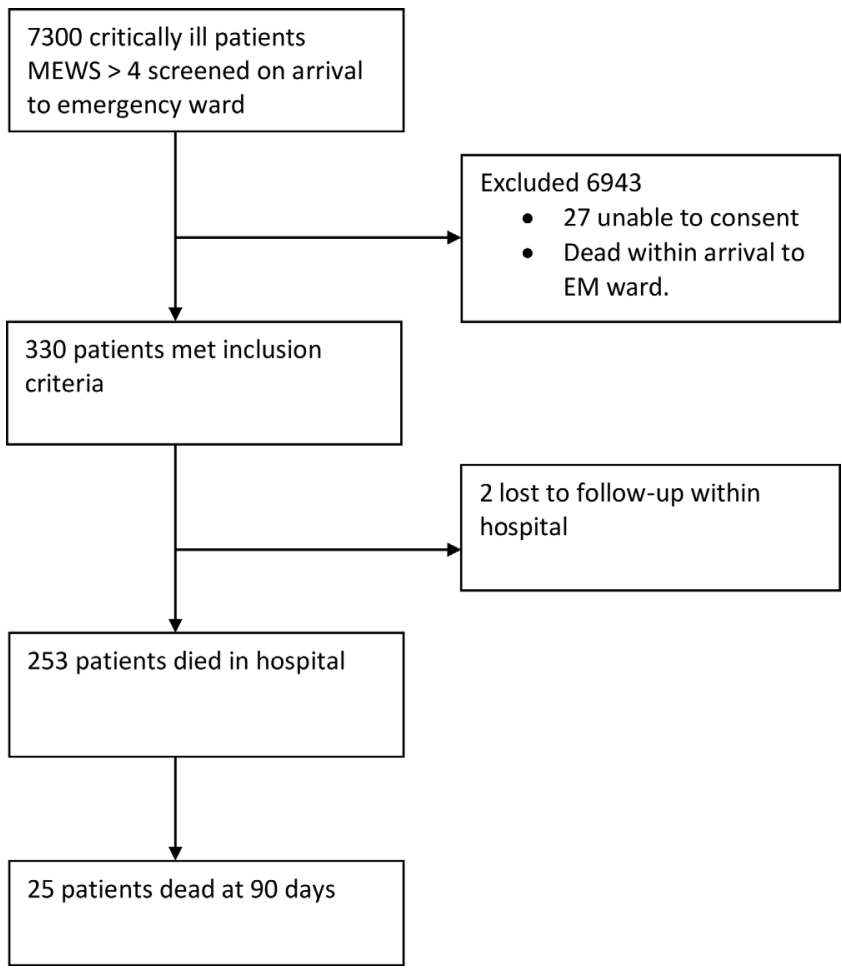

Figure 1 Flow chart of study participants. EM, Emergency Medicine; MEWS, Modified Early Warning Score.

Cardiac disease was present in $28(8.5 \%)$ and asthma in $6(1.8 \%)$ study participants. The most common cause of AHRF was pneumonia among 271 (82.6\%). Co-infection with HIV was present in $101(30 \%)$ of the participants. The mean plethysmographic oxygen saturation by pulse oximetry (on room air) was $77.6 \%$ (SD 12.7); mean $\mathrm{SpO}_{2} / \mathrm{FiO}_{2}$ ratio 193.9 (SD 31.8); mean LIPS 6.7 (SD 0.8 ). Only $6 \%$ of the participants were admitted to the ICU where they received invasive mechanical ventilation.

Regarding mortality (table 2), 253 (77\%) of the study participants died in hospital while cumulative mortality at 90-day follow-up was $85 \%$. Using modified Poisson regression analysis, severity of hypoxaemia (RR 1.29 (95\% CI 1.15 to 1.54 ), $\mathrm{p}=0.01$ ); a high LIPS (RR 1.79 (95\% CI 1.14 to 2.83), $\mathrm{p}=0.01$ ); thrombocytopenia (defined as $<100$ ) (RR 1.23 (95\% CI 1.11 to 1.38 ), $\mathrm{p}=0.01$ ); anaemia (RR 1.15 (95\% CI 1.01 to 1.31), p=0.03); HIV-positive status (RR 0.84 (95\% CI 0.72 to 0.97 ), $\mathrm{p}=0.019$ ) and being male (RR 1.15 (95\% CI 1.01 to 1.31 ), $\mathrm{p}=0.04$ ) were independently associated with 90-day mortality (table 3 ). We found no statistically significant difference between mortality among those who received ICU care and those who did not. Unlike other studies, we did not find an association between older age and mortality.

\section{DISCUSSION}

Our study showed that AHRF was prevalent and associated with a high mortality in our population. The risk factors for death were pneumonia, severity of hypoxaemia, high 


\begin{tabular}{|c|c|}
\hline Characteristic & N (\%)/327 (100) \\
\hline & Demographics \\
\hline Age in years: median (IQR) & $38(27,52)$ \\
\hline Male & $197(60.1)$ \\
\hline Use firewood & $121(36.8)$ \\
\hline Smoking history & $50(15)$ \\
\hline Smoking pack years* & $0.95(0.63)$ \\
\hline History of asthma & $6(1.8)$ \\
\hline \multirow{2}{*}{$\begin{array}{l}\text { Previous history of acute lung injury } \\
\text { admission }\end{array}$} & $18(5.5)$ \\
\hline & $\begin{array}{l}\text { Diagnosis at } \\
\text { admission }\end{array}$ \\
\hline Pneumonia & $271(82.6)$ \\
\hline Cardiac disease & $28(8.5)$ \\
\hline Neurological disease & $85(25.9)$ \\
\hline HIV-positive & $101(30.8)$ \\
\hline \multirow[t]{2}{*}{ Sepsis } & $100(30.4)$ \\
\hline & $\begin{array}{l}\text { Clinical } \\
\text { characteristics } † \\
\text { Mean (SD) }\end{array}$ \\
\hline Lung Injury Prediction Score & $6.7(0.8)$ \\
\hline Heart rate & $117.8(22.8)$ \\
\hline Respiratory rate & $33.9(8.9)$ \\
\hline Mean arterial pressure $(\mathrm{mm} \mathrm{Hg})$ & $78.6(23.3)$ \\
\hline Temperature $\left({ }^{\circ} \mathrm{C}\right)$ & $37.2(1.1)$ \\
\hline Pulse oximetry $\left(\mathrm{SpO}_{2}\right)$ & $77.6(12.7)$ \\
\hline $\mathrm{SpO}_{2} / \mathrm{F}$ ratio & $193.9(31.8)$ \\
\hline White cell count $\left(10^{9} / \mathrm{L}\right) \ddagger$ & $11.9(8.3)$ \\
\hline Haemoglobin status g/dLł & $11.1(3.9)$ \\
\hline Platelet count $\left(10^{9} / \mathrm{L}\right) \ddagger$ & $243.2(139.1)$ \\
\hline
\end{tabular}

${ }^{*}$ Pack years (SD).

†Worst values were recorded in the 24 hours.

¥While patients got a full blood count done free of charge, only 313/327 had Full Blood Count results available.

LIPS, HIV co-infection, anaemia, thrombocytopenia and being male.

We conducted a period prevalence study because considering the resource limitations it was operationally less complex as compared with the cohort or case-control study.

Our patients were predominantly male, of a similar age range as African studies, but much younger than patients in high-income countries (HICs). ${ }^{9} 10$

The prevalence of AHRF in our study population was low. This is slightly similar to a study done in Rwanda in which hypoxia was found in $8 \%$ of hospitalised patients. The Kigali Study screened 1046 hospitalised patients over a 6 -week period. This was lower than that reported in the Scandinavian and LUNGSAFE studies which reported incidences of AHRF of $23 \%$ and $34 \%$, respectively.
However, the LUNGSAFE Study did have some middleincome country data.

The main cause of AHRF in our study population was lower respiratory tract infection (LRTI). The majority of our study participants had pneumonia as a diagnosis. Community-acquired bacterial pneumonia was the most common cause of ARDS in data from other studies in the African setting. ${ }^{11}$

These findings concur with data suggesting that a young adult with LRTI in an LIC has a much higher odds of dying compared with one with LRTI in a high-income country. ${ }^{2}$ Similar findings were reported in the Rwanda Study where the most common underlying cause of respiratory failure was infection. Our study however, found that none of the participants was assessed for microbiological aetiology.

Our study found mortality to be very high among patients with AHRF. This was higher than that reported in the Kigali Study. This was even much higher than that reported in both the Scandinavian and the LUNGSAFE (Large observational study to Understand the Global Impact of Severe Acute Respiratory failure) studies, even though in these studies, mortality was almost identical between the patients with non-ARDS acute respiratory failure and patients with mild or moderate ARDS. ${ }^{2}{ }^{4}$ Mortality among our patients was higher than the overall mortality among adult patients admitted to the Mulago National Referral and Teaching Hospital with non-respiratory acute illness (from an audit conducted at the same time, the mortality rate for non-AHRF acutely ill patients was $48 \%$ ).

The high mortality in our study may be explained by the fact that our patients were very sick. This may be evidenced by the fact that LIPS was very high; that patients were severely hypoxaemic at presentation; and that due to resource constraints (such as lack of ICU beds, fluid monitoring, etc) most of our patients who would have benefited from intensive care, were not able to access it.

LIPS has been used to identify patients at risk of developing ARDS. In that study, a cut-off of $\geq 4$ predicted having ARDS or death. ${ }^{7}$ In our study, the average LIPS was more than 2 points above that cut-off. LIPS maybe useful in helping identify those high-risk patients in whom low cost interventions would possibly save, given the limited and often expensive treatment options available once ARDS has developed.

Severity of hypoxaemia is a predictor of mortality among patients with ARDS. ${ }^{12}$ Severe hypoxaemia $\left(\mathrm{PaO}_{2} /\right.$ $\mathrm{FiO}_{2}<100 \mathrm{~mm} \mathrm{Hg}$, at a PEEP (Positive End Expiratory Pressure) of $5 \mathrm{~cm} \mathrm{H}_{2} \mathrm{O}$ ), has been found in 20\%-30\% of patients with ARDS and is associated with the highest mortality rate. ${ }^{13}$ The mean non-invasive $\mathrm{SpO}_{2}$ in our study was $77 \%$. Additionally, we also used the $\mathrm{SpO}_{2} /$ $\mathrm{FiO}_{2}$ ratio to determine the severity of hypoxaemia. This is now a widely accepted non-invasive method to determine severity of hypoxaemia in hypoxic acute lung disease. ${ }^{81415}$ The mean $\mathrm{SpO}_{2} / \mathrm{FiO} 2$ ratio (193.9) in our study suggests that the majority of our study patients, and 


\section{Table 2 Bivariate analysis of factors associated with mortality}

\begin{tabular}{|c|c|c|c|c|}
\hline Characteristic & $\begin{array}{l}\text { Outcome } \\
\text { n (\% row) }\end{array}$ & & $\begin{array}{l}\text { Crude risk ratio } \\
(95 \% \mathrm{Cl})\end{array}$ & $P$ value \\
\hline & Dead & Alive & & \\
\hline & $254(77.7)$ & $73(22.3)$ & & \\
\hline \multicolumn{5}{|l|}{ Sex } \\
\hline Female & $97(74.6)$ & $33(25.4)$ & 1 & \\
\hline Male & $157(79.7)$ & $40(20.3)$ & $1.07(0.94$ to 1.21$)$ & 0.293 \\
\hline \multicolumn{5}{|c|}{$\begin{array}{l}\text { Previous history of acute lung injury } \\
\text { admission }\end{array}$} \\
\hline No & $240(77.7)$ & 69 (22.3) & 1 & \\
\hline Yes & $14(77.8)$ & $4(22.2)$ & $1.00(0.78$ to 1.29$)$ & 0.991 \\
\hline \multicolumn{5}{|l|}{ Smoked } \\
\hline No & $215(77.6)$ & $62(22.4)$ & 1 & \\
\hline Yes & 39 (78.0) & $11(22.0)$ & $1.00(0.86$ to 1.18$)$ & 0.952 \\
\hline \multicolumn{5}{|l|}{ Had asthma } \\
\hline No & 250 (77.9) & $71(22.1)$ & 1 & \\
\hline Yes & $4(66.7)$ & $2(33.3)$ & $0.86(0.48$ to 1.51$)$ & 0.593 \\
\hline \multicolumn{5}{|l|}{ Had pneumonia } \\
\hline No & $44(77.2)$ & $13(22.8)$ & 1 & \\
\hline Yes & $210(77.8)$ & 60 (22.2) & 1.01 (0.86 to 1.18$)$ & 0.924 \\
\hline \multicolumn{5}{|l|}{ Had a cardiac disease } \\
\hline No & 234 (78.3) & $65(21.7)$ & 1 & \\
\hline Yes & $20(71.4)$ & $8(28.6)$ & 0.91 (0.72 to 1.16$)$ & 0.459 \\
\hline \multicolumn{5}{|l|}{ Neuro } \\
\hline Yes & $186(76.9)$ & $56(23.1)$ & 1 & \\
\hline No & $68(80.0)$ & $17(20.0)$ & $1.04(0.92$ to 1.18$)$ & 0.536 \\
\hline \multicolumn{5}{|l|}{ Liver } \\
\hline No & $245(77.8)$ & 70 (22.2) & 1 & \\
\hline Yes & $9(75.0)$ & $3(25)$ & 0.96 (0.69 to 1.34$)$ & 0.830 \\
\hline \multicolumn{5}{|l|}{ HIV status } \\
\hline No & $179(79.2)$ & $47(20.8)$ & 1 & \\
\hline \multirow[t]{2}{*}{ Yes } & $75(74.3)$ & $26(25.7)$ & $0.94(0.82$ to 1.0 .7$)$ & 0.341 \\
\hline & Dead & Discharged & & \\
\hline \multicolumn{5}{|l|}{$\mathrm{SPO}_{2} / \mathrm{FiO}_{2}$} \\
\hline$<200$ & $139(88.0)$ & $19(12.0)$ & 1 & \\
\hline 201 or more & $115(68.1)$ & $54(31.9)$ & 0.77 (0.69 to 0.87 ) & $<0.001$ \\
\hline \multicolumn{5}{|l|}{ LIPS } \\
\hline Low & $14(48.3)$ & $15(51.7)$ & 1 & \\
\hline High (six or more) & $240(80.5)$ & $58(19.5)$ & 1.67 (1.14 to 2.44$)$ & 0.009 \\
\hline \multicolumn{5}{|l|}{ Heart rate } \\
\hline Normal & $41(74.6)$ & $41(25.4)$ & 1 & \\
\hline Abnormal $(>100)$ & 205 (77.9) & $58(22.1)$ & 1.05 (0.88 to 1.24$)$ & 0.602 \\
\hline \multicolumn{5}{|l|}{ Respiratory rate } \\
\hline & $26(81.3)$ & $6(18.7)$ & 1 & \\
\hline & 74 (76.3) & $23(23.7)$ & $0.94(0.77$ to 1.15$)$ & 0.538 \\
\hline & $154(77.8)$ & 44 (22.2) & $0.96(0.80$ to 1.15$)$ & 0.639 \\
\hline \multicolumn{5}{|l|}{ MAP } \\
\hline Normal & $168(72.4)$ & $64(27.6)$ & 1 & \\
\hline Abnormal $(<65)$ & $86(90.5)$ & $9(9.5)$ & 1.25 (1.13 to 1.39$)$ & $<0.001$ \\
\hline
\end{tabular}

Continued 


\begin{tabular}{|c|c|c|c|c|}
\hline Characteristic & $\begin{array}{l}\text { Outcome } \\
\text { n (\% row) }\end{array}$ & & $\begin{array}{l}\text { Crude risk ratio } \\
(95 \% \mathrm{Cl})\end{array}$ & $P$ value \\
\hline \multicolumn{5}{|l|}{$\mathrm{SPO}_{2} \%$} \\
\hline Normal (85+) & $77(64.2)$ & $43(35.8)$ & 1 & \\
\hline Abnormal & $177(85.5)$ & $30(14.5)$ & 1.33 (1.15 to 1.54$)$ & $<0.001$ \\
\hline \multicolumn{5}{|l|}{ WBC $\times 10 \mathrm{ul}$} \\
\hline Normal & $108(68.3)$ & $50(31.7)$ & $0.36(0.13$ to 0.98$)$ & 0.046 \\
\hline Abnormal $(>12000$ or $<4000)$ & $126(84.6)$ & $23(15.4)$ & 0.89 (0.30 to 2.60$)$ & 0.830 \\
\hline \multicolumn{5}{|l|}{ Haemoglobin (/dl) } \\
\hline Normal & $176(75.2)$ & $58(24.8)$ & 1 & \\
\hline Abnormal $(<8)$ & $55(83.3)$ & $11(16.7)$ & 1.11 (0.97 to 1.26$)$ & 0.124 \\
\hline \multicolumn{5}{|l|}{ Platelet count $\left(\times 10^{9} / \mathrm{ul}\right)$} \\
\hline Normal & $166(74.4)$ & $57(25.6)$ & 1 & \\
\hline Abnormal $(<100)$ & $29(96.7)$ & $1(3.3)$ & 1.30 (1.17 to 1.44$)$ & $<0.001$ \\
\hline
\end{tabular}

MAP, mean arterial pressure.

\begin{tabular}{|c|c|c|c|c|}
\hline Characteristic & $\begin{array}{l}\text { Crude risk ratio } \\
(95 \% \mathrm{Cl})\end{array}$ & $P$ value & $\begin{array}{l}\text { Adjusted risk ratio } \\
(95 \% \mathrm{Cl})\end{array}$ & $P$ value \\
\hline \multicolumn{5}{|l|}{ Sex } \\
\hline Female & 1 & & 1 & \\
\hline Male & 1.07 (0.94 to 1.21$)$ & 0.293 & 1.15 (1.01 to 1.31$)$ & 0.044 \\
\hline \multicolumn{5}{|l|}{ HIV status } \\
\hline No & 1 & & 1 & \\
\hline Yes & $0.94(0.82$ to 1.0 .7$)$ & 0.341 & 0.84 (0.72 to 0.97$)$ & 0.019 \\
\hline \multicolumn{5}{|l|}{ LIPS } \\
\hline Low & 1 & & 1 & \\
\hline High (6 or more) & 1.67 (1.14 to 2.44$)$ & 0.009 & 1.79 (1.14 to 2.83$)$ & 0.012 \\
\hline \multicolumn{5}{|l|}{ Heart rate } \\
\hline Normal & 1 & & 1 & \\
\hline Abnormal (>100) & 1.05 (0.88 to 1.24$)$ & 0.602 & 1.07 (0.89 to 1.29$)$ & 0.448 \\
\hline \multicolumn{5}{|l|}{ MAP } \\
\hline Normal & 1 & & 1 & \\
\hline Abnormal $(<65)$ & 1.25 (1.13 to 1.39$)$ & $<0.001$ & 1.09 (0.98 to 1.22$)$ & 0.125 \\
\hline \multicolumn{5}{|l|}{$\mathrm{SpO}_{2} \%$} \\
\hline Normal (85+) & 1 & & 1 & \\
\hline Abnormal $(<85)$ & 1.33 (1.15 to 1.54$)$ & $<0.001$ & $1.29(1.10$ to 1.51$)$ & 0.001 \\
\hline \multicolumn{5}{|l|}{ HBG/dl } \\
\hline Normal & 1 & & 1 & \\
\hline Abnormal $(<8)$ & 1.11 (0.97 to 1.26$)$ & 0.124 & 1.15 (1.01 to 1.31$)$ & 0.028 \\
\hline \multicolumn{5}{|c|}{ Platelet count (×109/ul) } \\
\hline Normal & 1 & & 1 & \\
\hline Abnormal $(<100)$ & $1.30(1.17$ to 1.44$)$ & $<0.001$ & 1.23 (1.11 to 1.38$)$ & $<0.001$ \\
\hline
\end{tabular}

LIPS, Lung Injury Prediction Score; MAP, mean arterial pressure. 
using the AECC (American European Consensus Conference) definitions, ${ }^{16}$ had acute lung injury (ALI).

HIV co-infection was associated with higher mortality from respiratory failure, as seen in previous studies in Uganda. ${ }^{17} 18$ The immunosuppressive state is known to predispose to aggressive opportunistic infections that cause respiratory and other organ failures. The significance of the association between anaemia and thrombocytopenia with mortality in our study explains the high rate of infection and possible pulmonary sepsis. In sepsis, a low platelet count is a well-known biomarker for disease severity. ${ }^{19}$ This (in addition to hypotension) highlights the high incidence of sepsis in this study population. Hypotension was also a predictor of mortality among patients with pneumonia in a study conducted in Malawi. ${ }^{20}$ We did not employ sepsis identification strategies at the time of the study. The focus was on treatment of infection and not necessarily sepsis as a syndrome. A limitation in our study was we did not document how much fluid was administered to patients. A randomised fluid trial in Zambia was stopped early for possible harm in the subgroup of patients with hypoxaemia and tachypnoea (who were receiving fluids). ${ }^{21} \mathrm{It}$ is possible that in our study population, fluids given to treat hypotension caused more harm. However, hypotension was not significantly associated with mortality at multivariate analysis.

Another possible explanation for the high mortality in our study was the lack of adequate resources to provide positive pressure ventilation to all patients that would benefit from it. Only $6 \%$ of the study participants received mechanical ventilation. Even then, mortality among them was still high. Some data suggest that mechanically ventilated patients in LICs have a higher mortality than those in HICs. ${ }^{22}$ Other resource constraints such as staffing, skills and delays in accessing care may explain this.

The Rwanda Study used a modification of the Berlin definition to achieve their primary objective. ${ }^{6}$ They found that about $50 \%$ of all patients with an $\mathrm{SpO}_{2} / \mathrm{FiO}_{2}$ ratio $\leq 315$ (where their estimate of $\mathrm{PaO}_{2} / \mathrm{FiO}_{2} \leq 300$ ) met their criteria for ARDS. Both the LUNGSAFE Study and a study looking at the impact of high-flow oxygen in severe respiratory failure found that the majority of hypoxic patients met the criteria for ARDS. ${ }^{23}$ Therefore, while our study was not able to apply the Berlin definition, it may seem logical that a large percentage of our hypoxic patients would have met clinical criteria for ARDS.

Our study had some limitations. Due to resource constraints, as previously documented, we were unable to perform arterial blood gas measurements in the study population. However, as documented earlier, we used a validated method to detect severity of hypoxaemia. We were unable to perform microbiological diagnoses such as blood cultures or sputum analyses. Other investigations were sporadic and inconsistent. We relied on clinicians' judgement for diagnosis data, but the ward system ensured that an internal medicine specialist had reviewed the working diagnosis. Another likely limitation is that we conducted a single-centre study. However, being a national referral hospital, the study site receives patients from all over the country.

Our study is probably the first of its kind in Africa to explore the prevalence and outcomes of AHRF in an adult population in a limited resource acute care setting.

The prevalence of AHRF among emergency department patients in a tertiary hospital in an LIC was low but was associated with very high mortality. Pneumonia was the most common cause of AHRF. Severity of HIV co-infection, hypoxaemia, high LIPS, anaemia, thrombocytopenia and being male were independently associated with death. This highlights the need for more work on early detection and management of AHRF in resourcelimited settings.

\section{Author affiliations}

${ }^{1}$ Anaesthesia and Critical Care, Makerere University College of Health Sciences, Kampala, Uganda

${ }^{2}$ Intensive Care, Mulago National Referral Hospital, Kampala, Uganda

${ }^{3}$ Internal Medicine, Makerere University Faculty of Medicine, Kampala, Uganda ${ }^{4}$ Respiratory medicine department, Royal Papworth Hospital NHS Foundation Trust, Cambridge, United Kingdom

${ }^{5}$ School of Public Health, Makerere University College of Health Sciences, Kampala, Uganda

${ }^{6}$ Immunology and Molecular Biology, Makerere University College of Health Sciences, Kampala, Uganda

${ }^{7}$ Office of the permanent secretary, Republic of Uganda Ministry of Health, Kampala, Uganda

${ }^{8}$ Dept of Medicine, University of Cambridge, Cambridge, UK

Contributors AK conceptualised and designed the study and analysed the data, CK, LN, DK, MJ JN and CS participated in study design and data collection. JT, NK and RS participated in data analysis. DA, DPK and CS participated in manuscript preparation. All authors read and approved the final manuscript.

Funding The study was funded by Wellcome Trust grant \# 107742/Z/15/Z and the UK government through the DELTAS Africa Initiative grant \#DEL-15-011 to THRiVE2.

Competing interests None declared.

Patient and public involvement Patients and/or the public were not involved in the design, or conduct, or reporting, or dissemination plans of this research.

Patient consent for publication Not required.

Ethics approval The protocol was reviewed and approved by the research and ethics committee of Mulago National Referral Hospital as well as the Makerere University School of biomedical sciences research and ethics committee.

Provenance and peer review Not commissioned; externally peer reviewed.

Data availability statement Data are available upon reasonable request.

Open access This is an open access article distributed in accordance with the Creative Commons Attribution 4.0 Unported (CC BY 4.0) license, which permits others to copy, redistribute, remix, transform and build upon this work for any purpose, provided the original work is properly cited, a link to the licence is given, and indication of whether changes were made. See: https://creativecommons.org/ licenses/by/4.0/.

ORCID iD

Arthur Kwizera http://orcid.org/0000-0002-7025-0465

\section{REFERENCES}

1 , Ranieri VM, Rubenfeld GD, et al, ARDS Definition Task Force. Acute respiratory distress syndrome: the Berlin definition. JAMA 2012;307:2526-33. 
2 Bellani G, Laffey JG, Pham T, et al. Epidemiology, patterns of care, and mortality for patients with acute respiratory distress syndrome in intensive care units in 50 countries. JAMA 2016;315:788-800.

3 Gattinoni L, Marini JJ, Quintel M. Time to rethink the approach to treating acute respiratory distress syndrome. JAMA 2018;319:664-6.

4 Luhr OR, Antonsen K, Karlsson M, et al. Incidence and mortality after acute respiratory failure and acute respiratory distress syndrome in Sweden, Denmark, and Iceland. The ARF Study Group. Am J Respir Crit Care Med 1999;159:1849-61.

5 Murthy S, Adhikari NK. Global health care of the critically ill in lowresource settings. Ann Am Thorac Soc 2013;10:509-13.

6 Riviello ED, Kiviri W, Twagirumugabe T, et al. Hospital incidence and outcomes of the acute respiratory distress syndrome using the Kigali modification of the Berlin definition. Am J Respir Crit Care Med 2016;193:52-9.

7 Gajic O, Dabbagh O, Park PK, et al. Early identification of patients at risk of acute lung injury: evaluation of lung injury prediction score in a multicenter cohort study. Am J Respir Crit Care Med 2011;183:462-70.

8 Pandharipande PP, Shintani AK, Hagerman HE, et al. Derivation and validation of Spo2/Fio2 ratio to impute for $\mathrm{Pao2} / \mathrm{Fio} 2$ ratio in the respiratory component of the sequential organ failure assessment score. Crit Care Med 2009;37:1317-21.

9 Brun-Buisson C, Minelli C, Bertolini G, et al. Epidemiology and outcome of acute lung injury in European intensive care units. results from the ALIVE study. Intensive Care Med 2004;30:51-61.

10 Bersten AD, Edibam C, Hunt T, et al. Incidence and mortality of acute lung injury and the acute respiratory distress syndrome in three Australian states. Am J Respir Crit Care Med 2002:165:443-8.

11 Piantadosi CA, Schwartz DA. The acute respiratory distress syndrome. Ann Intern Med 2004;141:460-70.

12 Go L, Budinger GRS, Kwasny MJ, et al. Failure to improve the oxygenation index is a useful predictor of therapy failure in acute respiratory distress syndrome clinical trials. Crit Care Med 2016;44:e40-4.
13 Vercesi V, Pisani L, van Tongeren PSI, et al. External confirmation and exploration of the Kigali modification for diagnosing moderate or severe ARDS. Intensive Care Med 2018;44:523-4.

14 Chen W, Janz DR, Shaver CM, et al. Clinical characteristics and outcomes are similar in ARDS diagnosed by oxygen Saturation/Fio2 ratio compared with Pao2/Fio2 ratio. Chest 2015;148:1477-83.

15 Pisani L, Roozeman J-P, Simonis FD, et al. Risk stratification using $\mathrm{SpO} 2 / \mathrm{FiO}_{2}$ and PEEP at initial ARDS diagnosis and after $24 \mathrm{~h}$ in patients with moderate or severe ARDS. Ann Intensive Care 2017;7:108

16 Bernard GR, Artigas A, Brigham KL, et al. Report of the AmericanEuropean consensus conference on acute respiratory distress syndrome: definitions, mechanisms, relevant outcomes, and clinical trial coordination. consensus Committee. J Crit Care 1994:9:72-81.

17 Kwizera A, Nabukenya M, Peter A, et al. Clinical characteristics and short-term outcomes of HIV patients admitted to an African intensive care unit. Crit Care Res Pract 2016;2016:2610873-7.

18 Worodria W, Chang E, Andama A, et al. Predictors of mortality among hospitalized patients with lower respiratory tract infections in a high HIV burden setting. J Acquir Immune Defic Syndr 2018;79:624-30.

19 Venkata C, Kashyap R, Farmer JC, et al. Thrombocytopenia in adult patients with sepsis: incidence, risk factors, and its association with clinical outcome. J Intensive Care 2013;1:9.

20 Birkhamshaw E, Waitt CJ, Innes M, et al. Severity assessment of lower respiratory tract infection in Malawi: derivation of a novel index (SWAT-Bp) which outperforms CRB-65. PLoS One 2013;8:e82178.

21 Andrews B, Semler MW, Muchemwa L, et al. Effect of an early resuscitation protocol on in-hospital mortality among adults with sepsis and hypotension: a randomized clinical trial. JAMA 2017;318:1233-40.

22 Azevedo LCP, Park M, Salluh JIF, et al. Clinical outcomes of patients requiring ventilatory support in Brazilian intensive care units: a multicenter, prospective, cohort study. Crit Care 2013;17:R63.

23 Frat J-P, Thille AW, Mercat A, et al. High-Flow oxygen through nasal cannula in acute hypoxemic respiratory failure. $N$ Engl $\mathrm{J} \mathrm{Med}$ 2015;372:2185-96. 